\title{
DO CRIME DE MAUS-TRATOS CONTRA OS ANIMAIS E O DIREITO PENAL SIMBÓLICO: ANÁLISE DO SIMBOLISMO PENAL NA CRIAÇÃO DA LEI No 14.064 DE 2020
}

\section{Maria Luísa Brasil Gonçalves Ferreira* Luiz Gustavo Gonçalves Ribeiro**}

\section{RESUMO}

O objetivo do artigo foi avaliar se a Lei no 14.064 de 2020 é expressão de Direito Penal simbólico ou se efetivamente atende à função preventiva inerente ao direito penal, a partir da hipótese de que a lei, por visar responder aos anseios sociais de recrudescimento da pena para maus tratos de animais, é dotada de alto grau de simbolismo em sua criação. Foi empregada metodologia dedutiva, analítica e dogmática e consultadas legislação pertinentes ao tema, bem como doutrinas especializadas em direito penal e direito ambiental. Concluiu-se que a criação da Lei se reveste de alto grau de simbolismo.

Palavras-chave: Direto Penal; Direito Ambiental; Fauna; Punitivismo; Simbolismo Penal.

\section{THE CRIME OF MISTRACT AGAINST ANIMALS AND SYMBOLIC CRIMINAL LAW: ANALYSIS OF CRIMINAL SYMBOLISM IN THE CREATION OF LAW N 14.064 OF 2020}

\section{ABSTRACT}

The article set out to assess whether Law No. 14.064 of 2020 is an expression of symbolic Criminal Law or whether it effectively fulfills the functions of criminal law, based on the hypothesis that the law, by aiming to respond to the social desires of increasing the penalty for bad animal treatment, is endowed with a high degree of symbolism in its creation. Deductive, analytical and dogmatic methodology was used, with bibliographic and documentary research technique. It was concluded that the creation of the Law has a high degree of symbolism, requiring quantitative research to evaluate its effectiveness.

Keywords: Criminal Law; Environmental Law; Fauna; Enviroment; Criminal Symbolism.

\section{INTRODUÇÃO}

À luz dos princípios que regem o direito penal, e considerando a tendência legislativa crescente em responder penalmente aos anseios sociais, a presente pesquisa busca responder ao seguinte tema-problema: a Lei 14.064/2020 é uma expressão de direito penal simbólico ou corresponde às expectativas de direito penal preventivo?

A hipótese que se busca comprovar é a de que a lei editada é dotada de alto grau de simbolismo, voltada ao atendimento de exigências punitivistas da opinião pública, possuindo

\footnotetext{
* Mestranda em Direito pela Escola Superior Dom Helder Câmara. Assistente jurídico na 6 a Câmara Criminal do Tribunal de Justiça de Minas Gerais. E-mail: mlbrasil43@ gmail.com.

*** Doutor em Direito pela Universidade Federal de Minas Gerais, Brasil. Promotor de Justiça do Ministério Público do Estado de Minas Gerais. Professor dos cursos de Mestrado e Doutorado em Direito Ambiental e Desenvolvimento Sustentável da Escola Superior Dom Helder Câmara. E-mail: lgribeirobh@ gmail.com.
} 
caráter predominantemente simbólico. A partir do tema-problema colocado e da hipótese, identifica-se o objetivo geral da pesquisa que é analisar se a alteração legislativa à Lei de Crimes Ambientais materializada na Lei 14.064/2020 é expressão de direito penal simbólico ou se atende às expectativas de direito penal preventivo.

Para atingir o objetivo macro, emerge a necessidade de enfrentar temas de direito penal ambiental que possibilitarão maior afinidade com o tema e darão subsídio aos questionamentos levantados. Dessa forma, os objetivos específicos da pesquisa são: apresentar breves noções sobre o direito penal simbólico sobre a necessidade de criação de um Direito Penal alicerçado na Constituição Federal e no Estado Democrático de Direito; evidenciar o mandamento constitucional de tutela penal do meio ambiente e a necessidade de proteção da fauna como um todo; apresentar a tramitação do projeto de lei que culminou na publicação da Lei 14.064/2020; e, por fim, avaliar os indícios de simbolismo penal no discurso que motivou a edição da referida Lei.

A pesquisa é qualitativa, com método descritivo-dedutivo, partindo da análise dos conceitos gerais de direito penal simbólico e proteção da fauna e posterior análise da Lei $\mathrm{n}^{\circ}$ 14.064/2020 e o simbolismo nela presente. A técnica adotada é a pesquisa bibliográfica e documental, com leitura de doutrinas, artigos científicos e legislações pertinentes que contribuam para o desenvolvimento do tema.

A justificativa para pesquisa parte do anseio em cumprir o mandamento constitucional de criminalização das condutas lesivas ao meio ambiente, sem perder de vista o Direito Penal como ultima ratio, como forma de evitar o autoritarismo estatal contrário ao Estado Democrático de Direito. Espera-se que os produtos deste trabalho contribuam para o Direito Penal Ambiental, por considerar inevitável que a proteção ao meio ambiente seja efetivada racionalmente, afastando a produção legislativa de discursos falaciosos para atender à opinião pública e midiática.

\section{SIMBOLISMO PENAL E O RISCO AO ESTADO DEMOCRÁTICO DE DIREITO}

O Direito Penal se presta a controlar comportamentos sociais, estabelecendo os limites de atuação indivíduo, sendo a única instância capaz de exercer este controle. Configura-se, portanto, como única instância de controle social formalizado, exercido por meio de poder coercitivo, visando à proteção de bens jurídicos especialmente relevantes.

Não se ignora que o contexto social influencia na criação de normas penais e seletividade dos bens jurídicos. Entretanto, o Direito Penal não pode ser alicerçado tão 
somente no atendimento às expectativas sociais e da opinião pública, sob pena de falência do Estado Democrático de Direito. Conforme leciona Jesus-María Silva Sánchez, a partir das tendências doutrinárias à defesa do direito penal mínimo:

[...] realmente não é nada difícil constatar a existência de uma tendência claramente dominante em todas as legislações no sentido da introdução de novos tipos penais, assim como um agravamento dos já existentes, que se pode encaixar no marco geral da restrição, ou a "reinterpretação" das garantias clássicas do Direito Penal substantivo e do Direito Processual Penal. (SÂNCHEZ, 2011, p. 28).

$\mathrm{O}$ autor entende que a atual tendência expansiva do Direito Penal diverge daquela da década de 70, marcada pelo movimento "Lei e Ordem". Partindo da análise da política criminal à luz da globalização, o autor enumera dez causas da expansão do direito penal ${ }^{\dagger}$, afirmando que "a divisão social característica dos debates clássicos sobre o Direito Penal foi substituída por um consenso geral, ou quase geral, sobre as "virtudes" do Direito Penal como instrumento de proteção dos cidadãos.” (SÁNCHEZ, 2011, p. 32).

O simbolismo penal foge à função do Direito Penal e à instrumentalidade necessária para aplicação da norma, moldando-se às exigências da sociedade e da opinião pública, lastreando-se em discursos políticos falaciosos. A norma penal deve demonstrar necessidade prática de sua intervenção, legitimando-se quando atinge a função de prevenção às condutas delitivas. Nesse sentido, o alto grau de simbolismo de uma norma penal conduz à crise de legitimidade do direito penal como um todo, na medida em que se afasta da instrumentalidadee do empirismo.

De outro lado, Hassemer demonstra preocupação com as críticas ao simbolismo penal e a busca pela censura absoluta ao caráter simbólico da norma. O autor considera inevitável que as normas penais possuam alguns fins simbólicos, alertando que a crítica deve se afastar de análise meramente teórica, evidenciando a necessidade de se analisar a "face negativa do direito penal simbólico":

\footnotetext{
Neste ponto, é o elemento do engano que ganha especial atenção de Hassemer, para quem a falsa aparência de efetividade e de instrumentalidade da lei penal deve ser analisada sob o ponto de vista da qualidade objetiva da norma. Isso quer dizer que a aplicação da norma simbólica resulta no alcance de objetivos diversos daqueles nela descritos. No caso da norma penal, o que se espera como função manifesta é a proteção do bem jurídico nela previsto. (ALVES, 201, p. 41, grifo nosso).
}

\footnotetext{
† São elas: surgimento de novos interesses, efetivo aparecimento de novos riscos, institucionalização da insegurança, sensação social de insegurança, configuração de uma sociedade de "sujeitos passivos", identificação da maioria como vítima do delito, descrédito de outras instâncias de proteção, gestores "atípicos" da moral, atitude da esquerda política e gerencialismo (SÁNCHEZ, 2011).
} 
Dessa forma, a função de analisar o caráter simbólico de determinada norma penal é árdua. Não se pode olvidar que a norma penal é orientada a conter determinado comportamento social que lesione bem jurídico penalmente relevante, sendo "indispensável o exame de se ela responde à sua funcionalidade, à sua instrumentalidade" (ALVES, 201, p. 42), bem como se atende aos princípios limitadores do poder punitivo do Estado.

Em razão da capacidade de atuação do Estado para cercear o direito fundamental à liberdade, a normal penal deve delimitar as relações entre o poder de intervenção do Estado e a liberdade individual, respeitando-se princípios constitucionais limitadores do poder punitivo estatal. O poder punitivo estatal deve proteger os bens jurídicos que tem relevância social, sobretudo àqueles que são inerentes à existência humana, respeitando parâmetros constitucionais.

A política criminal, portanto, é essencial para dar sentido ao sistema jurídico-penal, legitimando a atuação coercitiva do Estado, evitando-se o autoritarismo estatal. Nesse sentido, o Direito Penal deve ser estudado e criado à luz do Estado Democrático de Direito, com vistas à efetivação de direitos e garantias fundamentais de liberdades individuais e direitos políticos e sociais.

O princípio da "ultima ratio", também denominado princípio da intervenção mínimo, orienta o legislador a restringir a criação de tipos penais para tutela de bem jurídicos relevantes. Se outras esferas do direito, como a civil ou a administrativa, forem suficientes para proteção do bem jurídico, a tutela penal é desnecessária e não recomendável. O referido princípio também orienta a atuação do Poder Judiciário, uma vez que, de acordo com Zaffaroni, "o sistema orientador que é proposto aos juízes deve ter como objeto conter e reduzir o poder punitivo" (ZAFFARONI, p. 40, 2003), de forma a evitar o desaparecimento do Estado de Direito e da própria República.

A intervenção penal, portanto, deve ser limitada pelos objetivos de realização dos interesses sociais mais relevantes, implicando seletividade na indicação dos bens jurídicos que receberão tutela penal, de forma que a incriminação só se justifique quando houver ataque à bem jurídico socialmente expressivo. Dessa forma, a criminalização de condutas, por si, não importa em violação ao princípio da "ultima ratio", justificando-se quando houver lesão ou ameaça de lesão a bens jurídicos relevantes.

Nesta esteira, o princípio da fragmentariedade também é expressão da limitação do poder punitivo do Estado. Este princípio determina que o Direito Penal só se ocupe de uma 
parte dos bens jurídicos protegidos pelo ordenamento, restringindo-se àquelas "condutas mais graves e mais perigosas praticadas contra bens mais relevantes" (BITENCOURT, 2012, p.54). De acordo com Galvão (2013), não há como haver proteção integral do bem jurídico-penal, emergindo o caráter fragmentário do Direito Penal para proteção do bem jurídico em relação às formas mais graves de violação.

Por fim, o princípio da ofensividade, ou da exclusiva proteção de bem jurídico, também norteia a aplicação do Direito Penal. De acordo com este princípio, todo crime deve gerar lesão ou ameaça de lesão a determinado bem jurídico, pois não pode se punir condutas que não ultrapassem a esfera do autor. Nos dizeres de Bitencourt:

\begin{abstract}
O princípio da ofensividade no Direito Penal da pretensão de que seus efeitos tenham reflexos em dois planos: no primeiro, servir de orientação à atividade legiferante, fornecendo substratos político-jurídicos para que o legislador adote, na elaboração do tipo penal, a exigência indeclinável de que a conduta proibida represente ou contenha verdadeiro conteúdo ofensivo a bens jurídicos socialmente relevantes; no segundo plano, servir de critério interpretativo, constrangendo o intérprete legal a encontrar em cada caso concreto indispensável lesividade ao bem jurídico protegido. (BITENCOURT, 2012, p. 59-60).
\end{abstract}

Inegável, portanto, que o controle social exercido pelo Direito Penal deve se pautar nos princípios limitadores do poder punitivo estatal, visando tutelar bens jurídicos especialmente relevantes. Bem jurídico-penal, de acordo com Luiz Regis Prado (2014), é um dado ou valor social retirado do contexto social que é essencial para a coexistência e o desenvolvimento do ser humano, e por isso merece proteção jurídico-penal. A seleção dos bens e direitos a serem tutelados penalmente, bem como os caminhos para efetivação desta tutela, é realizada por meio da política criminal, da qual a Constituição Federal é a primeira manifestação.

Diante dos riscos do simbolismo penal apresentados e do mandamento constitucional de proteção e garantia do meio ambiente ecologicamente equilibrado, cabe tecer algumas considerações sobre a tutela penal do meio ambiente.

\title{
3 TUTELA PENAL DO MEIO AMBIENTE E A PROTEÇÃO DA FAUNA
}

É de se ressaltar, conforme demonstrado no capítulo anterior, que os bens jurídicopenais não permanecem estáticos no tempo. A mudança de contextos históricos e sociais, com o consequente surgimento de novos valores que demandem tutela jurídica, influencia na seletividade de bens jurídicos a serem tutelados. Por este motivo, os bens jurídicos não precisam estar listados taxativamente na Constituição, mas devem possuir um status 
constitucionalmente relevante, pois "em um Estado Democrático de Direito, a determinação dos valores da comunidade deve estar, em princípio, delineada na Constituição" (PRADO, 2014, p. 397).

Nessa esteira, a Constituição Federal de 1988 elegeu, dentre outros, o meio ambiente como bem jurídico penalmente tutelável. $\mathrm{O} \S 3^{\circ}$ do art. 225 da Constituição Federal preleciona que aquele que causar danos ao meio ambiente ficará sujeito à responsabilização nas esferas civil, penal e administrativa ${ }^{\ddagger}$, cabendo ao:

[...] legislador ordinário construir um verdadeiro sistema normativo penal que defina, de modo certo e taxativo, as condutas puníveis e respectivas penas, em harmonia com os princípios constitucionais penais, como estrutura jurídica mínima, para dar cumprimento ao estatuído na Constituição Federal. (PRADO, 2005, p. 83).

A amplitude do conceito de meio ambiente alinhada à necessidade de reserva legal torna necessária a seleção dos bens jurídicos ambientais a serem tutelados penalmente. Entretanto, não se pode olvidar que, ainda que exista um mandamento constitucional expresso de criminalização, evidente que o cumprimento da ordem emanada pela Constituição deve observar os princípios limitadores do poder punitivo do Estado, observando que o Direito Penal é instrumento de integração de direitos humanos e fundamentais.

A intervenção penal se justifica em razão da natureza de direito fundamental ao meio ambiente ecologicamente equilibrado e à sadia qualidade de vida, devendo ser considerado o meio ambiente em sua acepção global, uma vez que:

\begin{abstract}
O ambiente - elevado à categoria de bem jurídico essencial à vida, à saúde e à felicidade do homem - integra-se, em verdade, em um conjunto de elementos naturais, culturais e artificiais, de modo que possibilite o seguinte detalhamento: meio ambiente natural (constituído pelo solo, a água, o ar atmosférico, a flora, a fauna, enfim, a biosfera); meio ambiente cultural (integrado pelo patrimônio artístico, cultural, paisagístico, arqueológico, espeleológico, etc.); e meio ambiente artificial (formado pelo espaço urbano construído, consubstanciado no conjunto de edificações e nos equipamentos públicos: ruas, praças, áreas verdes, ou seja, todos os logradouros, assentamentos e reflexos urbanísticos, caracterizados como tal). Todos esses elementos estão definitivamente protegidos pelo Direito Penal, como se vê da nova arquitetura tipológica da Lei 9.605/1998. (MILARÉ, 2014, p. 468, grifo nosso).
\end{abstract}

A Lei $n^{\circ} 9.605$ de 1998 objetivou sistematizar a legislação relativa à tutela penal do meio ambiente e, além de dispor sobre infrações administrativas, tipificou as condutas lesivas

\footnotetext{
* Art. $225, \S 3^{\circ}$ As condutas e atividades consideradas lesivas ao meio ambiente sujeitarão os infratores, pessoas físicas ou jurídicas, a sanções penais e administrativas, independentemente da obrigação de reparar os danos causados. (BRASIL, 1988).
} 
ao meio ambiente estabelecendo sanções penais, organizando-se a partir dos objetos de tutela: fauna, flora, poluição e Administração Ambiental.

A fauna, de acordo com Milaré (2015), é o conjunto de animais próprios de um país ou região, dividindo-se em doméstica, domesticada e silvestre. São considerados como animais domésticos as "espécies que foram submetidas a processos tradicionais de manejo, possuindo características biológicas e comportamentais em estreita dependência do homem para sua sobrevivência" (MILARÉ, 2015, p. 492). A fauna domesticada é composta por espécies encontradas naturalmente, mas que dependem do ser humano para sua sobrevivência, podendo ou não manter suas características comportamentais de animais silvestres. Por fim, a fauna silvestre é aquela que possui habitat natural nas matas, florestas, rios, mares e, como regra geral, não possuem adaptabilidade natural ao convívio humano.

A proteção da fauna decorre do mandamento constitucional previsto no art. $225, \S 1^{\circ}$, VII, que atribui ao Poder Público o dever de proteção da fauna e da flora "vedadas, na forma da lei, as práticas que coloquem em risco sua função ecológica, provoquem a extinção de espécies ou submetam os animais a crueldade." (BRASIL, 1988). Nas lições de Luiz Regis Prado, o dispositivo constitucional "abarca todos os animais irracionais, independente da sua função ecológica, de sua nacionalidade ou do seu risco de extinção" (PRADO, 2005, p. 227).

Entretanto, apesar da Constituição Federal e do texto original do art. 32 da Lei 9.605/98 não fazerem distinção entre as espécies de animais tutelados, em 29 de setembro de 2020 foi sancionada a Lei $n^{\circ} 14.064$, denominada "Lei Sansão". Diante disso, cabe tecer considerações sobre a reforma legislativa implementada em 2020 e investigar se há indicativos de simbolismo penal na norma.

\section{DO CRIME DE MAUS-TRATOS AOS ANIMAIS}

A redação original do artigo 32 da Lei de Crimes Ambientais ${ }^{\S}$ estabelecia como crime a conduta de "praticar ato de abuso, maus-tratos, ferir ou mutilar animais silvestres, domésticos ou domesticados, nativos ou exóticos" e também a conduta de "realizar experiência dolorosa ou cruel em animal vivo" quando houver outra possibilidade. A pena

\footnotetext{
$\S$ Art. 32. Praticar ato de abuso, maus-tratos, ferir ou mutilar animais silvestres, domésticos ou domesticados, nativos ou exóticos: Pena - detenção, de três meses a um ano, e multa. $\S 1^{\circ}$ Incorre nas mesmas penas quem realiza experiência dolorosa ou cruel em animal vivo, ainda que para fins didáticos ou científicos, quando existirem recursos alternativos. $\S 2^{\circ}$ A pena é aumentada de um sexto a um terço, se ocorre morte do animal. (BRASIL, 1998). 
imposta era de detenção de 03 (três) meses a 01 (um) ano e multa, tratando-se de crime de menor potencial ofensivo.

Entretanto, apesar da Constituição Federal e do texto original do art. 32 da Lei 9.605/98 não fazerem distinção entre as espécies de animais tutelados, em 29 de setembro de 2020 foi sancionada a Lei $n^{\circ} 14.064$, denominada "Lei Sansão". A referida Lei tipificou os maus-tratos cometidos contra cães e gatos, dando ao artigo 32 da Lei 9.605/98 a seguinte redação:

\begin{abstract}
Art. 32. Praticar ato de abuso, maus-tratos, ferir ou mutilar animais silvestres, domésticos ou domesticados, nativos ou exóticos:

Pena - detenção, de três meses a um ano, e multa.

$\S 1^{\circ}$ Incorre nas mesmas penas quem realiza experiência dolorosa ou cruel em animal vivo, ainda que para fins didáticos ou científicos, quando existirem recursos alternativos.

$\$ 1^{\circ}$-A Quando se tratar de cão ou gato, a pena para as condutas descritas no caput deste artigo será de reclusão, de 2 (dois) a 5 (cinco) anos, multa e proibição da guarda. (Incluído pela Lei $\mathbf{n}^{\circ}$ 14.064, de 2020).

$\S 2^{\circ}$ A pena é aumentada de um sexto a um terço, se ocorre morte do animal. (BRASIL, 2020, grifo nosso).
\end{abstract}

O projeto de lei foi apresentado pelo deputado Fred Costa e a redação original do projeto não fazia distinção entre as espécies de animais tuteladas, tendo como objetivo "estabelecer pena de reclusão a quem praticar ato de abuso, maus-tratos, ferir ou mutilar animais silvestres, domésticos ou domesticados, nativos ou exóticos; e instituir penas para estabelecimentos comerciais ou rurais que concorrerem para a prática do crime" (BRASIL, 2019).

A justificação do projeto de lei, dentre outros motivos, foi consubstanciada na necessidade de maior tutela dos animais por meio do rigor da lei, uma vez que o crime era considerado de menor potencial ofensivo e punido com pena de detenção, que não comporta regime inicial fechado. $\mathrm{O}$ autor do projeto evidenciou ainda que:

Os animais não possuem meios de se defender, não são capazes de procurar os
seus direitos. A única maneira para que tais crimes sejam evitados é o empenho
da sociedade, que não deve aceitar tamanha barbaridade, exigindo que as
regras que visam reprimir esses crimes sejam cada vez mais rigorosas.
Outrossim é fundamental que estabelecimentos comerciais e rurais que permitam a
ocorrência de tais pecados sejam devidamente apenados, na medida da gravidade
do delito praticado. (BRASIL, 2019, p. 3 , grifo nosso).

O projeto foi apresentado ao Plenário da Câmara dos Deputados em 25 de fevereiro de 2019. Após criação de Comissão Especial e realização de audiências públicas com 
representantes de ONGs pelos direitos dos animais, ativistas e deputados, em 10 de dezembro de 2019, o deputado Fred Costa requereu apreciação imediata do projeto de lei, nos termos do art. 155 do Regimento Interno da Câmara dos Deputados**, o que foi deferido em 16 de dezembro de 2019.

O relator do projeto de lei, deputado Celso Sabino, votou pela aprovação do projeto de lei na forma do substitutivo por ele proposto, dando à proposição legislativa a seguinte redação:

\section{SUBSTITUTIVO AO PROJETO DE LEI Nº 1.095, DE 2019}

Aumenta as penas cominadas ao crime de maus-tratos aos animais quando se tratar de cão ou gato.

O Congresso Nacional decreta:

Art. $1^{\circ}$ Esta Lei aumenta as penas cominadas ao crime de maus-tratos aos animais quando se tratar de cão ou gato.

Art. $2^{\circ} \mathrm{O}$ art. 32 da Lei $\mathrm{n}^{\circ}$ 9.605, de 12 de fevereiro de 1998, passa a vigorar acrescido do seguinte $\S 2^{\circ}$, renumerando-se o atual $\S 2^{\circ}$ para $\S 3^{\circ}$ : “Art. 32 .

$\S 2^{\circ}$ Quando se tratar de cão ou gato, a pena para as condutas descritas no caput deste artigo será de reclusão, de dois a cinco anos, multa e proibição da guarda. " (NR)

Art. $3^{\circ}$ Esta Lei entra em vigor na data da sua publicação.

Verifica-se que o projeto de lei tramitou na Câmara dos Deputados, inclusive com a realização de audiência pública para debate do tema, consolidando-se o entendimento de maior rigor na punição ao crime de maus tratos contra animais. O parecer do relator evidencia esse entendimento e faz escorço histórico sobre a tutela da fauna na legislação brasileira e, ao longo do parecer, refere-se sempre aos animais como um todo, sem distinção entre as espécies. Apesar disso, o substitutivo apresentado, além de retirar a penalidade para as empresas, restringe o aumento de pena apenas para os crimes cometidos contra cães e gatos.

Apesar de não constar justificativa expressa para apresentação do substitutivo, o projeto foi aprovado nos moldes apresentados por seu relator e remetido ao Senado Federal em 19/12/2019. Em 11 de setembro de 2020 o projeto foi aprovado sem alterações pela Mesa Diretora do Senado, sendo remetido ao Presidente da República para sansão ou veto. A Lei foi sancionada em de 29 de setembro de 2020.

\footnotetext{
** Art. 155. Poderá ser incluída automaticamente na Ordem do Dia para discussão e votação imediata, ainda que iniciada a sessão em que for apresentada, proposição que verse sobre matéria de relevante e inadiável interesse nacional, a requerimento da maioria absoluta da composição da Câmara, ou de Líderes que representem esse número, aprovado pela maioria absoluta dos Deputados, sem a restrição contida no $\S 2^{\circ}$ do artigo antecedente.
} (BRASIL, 1989). 
A criação de leis penais para atender aos anseios sociais, sem legitimação instrumental da função punitiva, conduz à criação de leis carregadas de simbolismo penal, o que pode ser um risco ao Estado Democrático de Direito, conforme já analisado. Diante da preocupação com um direito penal expansivo que reforce o autoritarismo do Estado, cumpre analisar alguns sinais de simbolismo penal empregados na tramitação até aprovação da lei e sua aplicação.

\section{INDÍCIOS DE SIMBOLISMO PENAL}

O aumento da pena ao crime de maus-tratos cometidos contra cães e gatos impede a tramitação dos processos no Juizado Especial Criminal, em razão da pena mínima cominada ser superior a 01 (um) ano, tornando impossível a aplicação dos institutos despenalizadores ${ }^{\dagger \dagger}$, à exceção do acordo de não persecução penal previsto no art. 28-A do Código de Processo Penal $^{+\hbar}$. Além disso, permite a fixação de regime inicial fechado, em razão da natureza de reclusão atribuída ao delito ${ }^{\S \S}$. Também permite que seja decretada a prisão preventiva do agressor, nos termos do art. 313, I do Código de Processo Penal ${ }^{\text {**** }}$.

A tramitação da lei, em diversos momentos, apresenta exemplos de casos de maustratos e crueldade contra animais que ganharam repercussão na mídia e geraram comoção social. Após os casos ocorridos, com ampla divulgação pelos meios de comunicação, houve intensa manifestação nas redes sociais para punição dos agressores e recrudescimento da pena, indicando insatisfação social com relação às penalidades previstas para o crime de maus-tratos. Dentre as causas de expansão do direito penal propostas por Sánchez (2011) a causa número quatro parece encontrar exemplo na proposta legislativa analisada.

O autor destaca o papel das instituições públicas e dos meios de comunicação no reforço à sensação social de insegurança. Pondera que os meios de comunicação e as

\footnotetext{
${ }^{\dagger}$ Art. 89. Nos crimes em que a pena mínima cominada for igual ou inferior a um ano, abrangidas ou não por esta Lei, o Ministério Público, ao oferecer a denúncia, poderá propor a suspensão do processo, por dois a quatro anos, desde que o acusado não esteja sendo processado ou não tenha sido condenado por outro crime, presentes os demais requisitos que autorizariam a suspensão condicional da pena (art. 77 do Código Penal). (BRASIL, 1995).

\$ Art. 28-A. Não sendo caso de arquivamento e tendo o investigado confessado formal e circunstancialmente a prática de infração penal sem violência ou grave ameaça e com pena mínima inferior a 4 (quatro) anos, o Ministério Público poderá propor acordo de não persecução penal, desde que necessário e suficiente para reprovação e prevenção do crime, mediante as seguintes condições ajustadas cumulativa e alternativamente: (Incluído pela Lei no 13.964, de 2019) (BRASIL, 2019).

$\$$ Art. 33 - A pena de reclusão deve ser cumprida em regime fechado, semi-aberto ou aberto. A de detenção, em regime semi-aberto, ou aberto, salvo necessidade de transferência a regime fechado. (BRASIL, 1948).

Art. 313. Nos termos do art. 312 deste Código, será admitida a decretação da prisão preventiva: I - nos crimes dolosos punidos com pena privativa de liberdade máxima superior a 4 (quatro) anos. (BRASIL, 1941).
} 
instituições públicas não criam a sensação social de insegurança, mas reforçam ou estabilizam medos preexistentes, mas destaca que, de um lado, os meios de comunicação, por vezes, permitem que o receptor da mensagem tenha uma percepção inexata sobre a realidade que está próxima e sobre a realidade que está distante, além de, por meio da "reiteração da própria atitude (dramatização, morbidez) com a qual se examinam determinadas notícias atuam como um multiplicador dos ilícitos e catástrofes, gerando uma insegurança subjetiva que não se corresponde com o nível de risco objetivo”. (SÁNCHEZ, 2011, p. 48).

Inicialmente, verifica-se que uma das justificativas apresentadas pelo deputado Fred Costa para o projeto de lei está baseada em caso ocorrido em novembro de 2018, no qual um funcionário de um supermercado supostamente espancou e envenenou o cachorro Manchinha, ocasionando sua morte $\mathrm{e}^{\dagger \dagger}$ :

\begin{abstract}
Recentemente, a forma brutal como um cachorro foi morto dentro de um supermercado Carrefour, em Osasco, São Paulo, chocou o País. O animal foi espancado e envenenado por um segurança do local, no dia 28 de novembro passado, e acabou não resistindo aos ferimentos. Internautas, ativistas pelos direitos dos animais, celebridades e políticos se manifestaram publicamente contra o bárbaro crime. Uma mobilização fez com que cerca de um milhão e meio de pessoas assinassem uma petição exigindo a punição do funcionário. (BRASIL, 2019, p. 2, grifei).
\end{abstract}

O caso foi denominado pela imprensa como "Caso Manchinha", em razão do nome do animal morto de forma cruel. O supermercado firmou Termo de Ajustamento de Conduta com o Ministério Público de São Paulo, comprometendo-se a pagar um milhão de reais a ser depositado em fundo de para cuidados aos animais ${ }^{\text {tht }}$ A responsabilização penal do funcionário tramita no juizado especial criminal de Osasco/SP, por se tratar, à época de sua ocorrência, de crime de menor potencial ofensivo, na forma do art. 89 da Lei 9.099 de 1995.

Outro caso de repercussão foi utilizado para evidenciar a necessidade de tramitação da lei. $\mathrm{O}$ deputado Celso, relator do projeto, apresentou parecer favorável à norma, na forma do substitutivo colacionado no capítulo anterior, e, a fim de demonstrar urgência na tramitação do projeto, exemplificou:

\footnotetext{
†† Cachorro abandonado é envenenado e espancado por funcionário de Carrefour em Osasco, dizem ativistas. Disponível em: < https://g1.globo.com/sp/sao-paulo/noticia/2018/12/04/cachorro-abandonado-e-envenenado-eespancado-por-funcionario-de-hipermercado-em-osasco-dizem-ativistas.ghtml>. Acesso em 31 de mar. 2021.

\# Caso Manchinha: Carrefour terá de depositar R\$ 1 milhão em fundo para cuidados a animais. Disponível em: $<$ https://g1.globo.com/sp/sao-paulo/noticia/2019/03/15/caso-manchinha-carrefour-tera-de-depositar-r-1-milhaoem-fundo-para-cuidados-a-animais.ghtml>. Acesso em 31 de mar. 2021.
} 
Por fim, cumpre salientar, a fim de demonstrar a urgência da matéria, a ocorrência de um gravíssimo episódio envolvendo maus-tratos aos animais, publicado em matéria jornalística em veículo da imprensa no dia $15.12 .2019^{\S \S \S}$.

Conforme noticiado, a Polícia Civil do Paraná resgatou 19 cães da raça pit bull de uma rinha no estado de São Paulo na noite deste último sábado (dia 14.12). Eles estavam muito machucados. Outros foram encontrados mortos. Além disso, era servido churrasco de carne de cachorro aos participantes da rinha.

De acordo com a Polícia Civil, foram detidas 40 pessoas, que devem responder por associação criminosa, maus-tratos contra os animais e jogo de azar.

Pela legislação atual, no que tange ao crime de maus-tratos aos animais, os autores desses bárbaros atos incorrerão nas penas de detenção, de três meses a um ano, e multa.

$[\ldots]$

Assim, revela-se inadiável a necessidade de alteração dessa norma, a fim de inibir comportamentos tão cruéis como os acima relatados. (BRASIL, 2019, p. 935, grifo nosso).

Por fim, ainda que o caso que justificou a propositura da lei tenha sido o "Caso Manchinha", a lei sancionada recebeu o nome de "Lei Sansão", em referência a outro caso de crueldade contra animais. Um cão da raça pitbull teve as duas patas traseiras decepadas por uma foice no dia 06 de julho de 2020 em Confins, região metropolitana de Belo Horizonte/MG. O tutor do animal compartilhou a situação em sua rede social, o que causou comoção, fazendo com que vários ativistas pelos direitos dos animais, incluindo políticos, se manifestassem pela responsabilização do agressor ${ }^{* * * *}$.

A redação original do projeto de lei evidenciava a necessidade de maior rigor na proteção dos animais. Entretanto, a Lei efetivamente sancionada restringiu a qualificadora aos crimes praticados aos cães e gatos, o que vai de encontro à Constituição Federal que determina a proteção da fauna.

Para além da restrição da norma aos cães e gatos, a retirada da penalidade para empresas que cometem maus-tratos contra animais, vide aquelas que realizam testes cruéis com animais, também é exemplo da confusa intenção do legislador em proteger a fauna, aproximando-se da "política do espetáculo", criticada por Baratta, na qual "os políticos tomam boa parte das suas decisões com o objetivo de satisfazer a opinião pública, movida pelo senso comum, e não necessariamente para modificar a realidade com vistas à justiça ou interesse público" (ALVES, 2016, p. 41).

§§§ Polícia Civil estoura 'rinha' de cães em Mairiporã e prende 41 pessoas. Disponível em: < https://g1.globo.com/sp/sao-paulo/noticia/2019/12/15/policia-civil-estoura-rinha-de-caes-em-mairipora-eprende-40-pessoas.ghtml>. Acesso em 02 de abril de 2021.

Cachorro tem as patas decepadas a golpes de foice por vizinho em Confins. Disponível em: < https://www.otempo.com.br/cidades/cachorro-tem-as-patas-decepadas-a-golpes-de-foice-por-vizinho-emconfins-1.2357345>. Acesso em 02 de abril de 2021. 
Estabelecendo um comparativo perfunctório entre tipos penais com a mesma pena imposta para o crime de maus-tratos, tem-se o crime de corrupção de menores, previsto no art. 218 do Código Penal. A pena é superior, inclusive, ao crime de maus-tratos contra a pessoa, previsto no art. 136 do Código Penal. A alteração legislativa abre espaço para defesa de teses de recrudescimento das penas dos crimes previstos no Código Penal, conforme defende Aguiar: "se o crime de maus-tratos à criança é apenado com detenção de dois meses a um ano, e multa, este também deveria ser corrigido assim como se propõe a correção dos maustratos a animais.” (AGUIAR, 2020, p. 2018).

A crítica apresentada pela autora exemplifica o que Silva Sánchez (2011) chama de gestores atípicos da moral. De acordo com o autor, associações ecologistas, feministas, de consumidores, entre outras, adquiriram papel de gestores da moral coletiva e "encabeçam a tendência de uma progressiva ampliação do Direito Penal no sentido de uma crescente proteção de seus respectivos interesses” (SÁNCHEZ, 2011, p. 82). Sánchez evidencia que as instituições, outrora abolicionistas, reclamam cada vez mais pela intervenção penal. Dessa forma, se de um lado há necessidade de tutela dos animais, em razão de sua vulnerabilidade, a proposta de aumento da pena do mesmo crime cometido contra a pessoa fomenta a expansão do direito penal violando, inevitavelmente, os princípios limitadores do poder punitivo estatal, já mencionados.

Por fim, reforçando os indicativos de caráter simbólico da legislação, é de se destacar que, em 01 de outubro de 2020, dois dias após publicação da Lei n 14.064 de 2020, os meios de comunicação divulgaram a primeira prisão pela suposta prática do crime previsto no art. $32, \S 1^{\circ}$ da Lei de Crimes Ambientais ${ }^{\dagger \dagger \dagger}$. A espetacularização da prisão da suposta agressora dos animais sugere ao destinatário da reportagem que a legislação surtiu efeitos em velocidade recorde, reforçando a ideia de que a criminalização e o recrudescimento das penas são soluções para os problemas sociais. Entretanto, considerando que a legislação está vigente há pouco mais de 06 (seis) meses, necessário realização de pesquisa quantitativa que se

\footnotetext{
†† Polícia faz primeira operação contra maus-tratos de animais em BH após 'Lei Sansão'. Disponível em: <https://www.hojeemdia.com.br/horizontes/pol\%C3\%ADcia-faz-primeira-opera\%C3\%A7\%C3\%A3o-contramaus-tratos-de-animais-em-bh-ap\%C3\%B3s-lei-sans\%C3\%A3o-1.806131>. Acesso em 02 de abril de 2021. Mulher é presa em Belo Horizonte suspeita de maus-tratos a animais, em $1^{\text {a }}$ operação após Lei Sansão. Disponível em: <https://g1.globo.com/mg/minas-gerais/noticia/2020/10/01/mulher-e-presa-em-belo-horizontesuspeita-de-maus-tratos-a-animais-em-1a-operacao-apos-lei-sansao.ghtml> . Acesso em 02 de abril de 2021.

Mulher é detida em BH por maus-tratos a cães, na primeira operação após publicação da Lei Sansão. Disponível em: < https://www.em.com.br/app/noticia/gerais/2020/10/01/interna_gerais,1190610/mulher-e-detida-em-bhpor-maus-tratos-a-caes-na-primeira-operacao-apo.shtml>. Acesso em 02 de abril de 2021.
} 
comprometa a avaliar os impactos da legislação nos crimes de maus-tratos cometidos contra cães e gatos.

Evidente que a alteração legislativa representou recrudescimento no tratamento daquele que praticar crueldade com cães e gatos, podendo ser a pena aplicada em dobro caso resulte em morte do animal. Contudo, remanesce a dúvida sobre a real intenção do legislador em tutelar a fauna como um todo, uma vez que, sem motivo aparente, restringiu o aumento da pena a espécies determinadas.

Inequívoco que casos de repercussão mencionados na pesquisa são dotados de especial gravidade e reclamam pela intervenção penal, não se defendendo aqui que a tutela penal da fauna seja desnecessária. De um lado, vislumbra-se a evidente necessidade de tutela penal do meio ambiente, em razão do mandamento constitucional expresso de criminalização e do reconhecimento do meio ambiente ecologicamente equilibrado como direito fundamental inerente à própria condição humana. De outro lado, o princípio da intervenção mínima demanda maior racionalidade na produção legislativa, afastando-se a criação de tipos penais que busquem atender exigências punitivistas da opinião pública e midiática.

\section{CONSIDERAÇÕES FINAIS}

Considerando que este trabalho se propôs a avaliar o grau de simbolismo penal existente na Lei $\mathrm{n}^{\circ}$ 14.064/20, partindo da hipótese que a referida Lei é dotada de alto grau de simbolismo penal, afastando-se do caráter preventivo do Direito Penal, algumas conclusões são possíveis.

A primeira conclusão parte da necessidade de análise da tutela penal do meio ambiente à luz dos princípios limitadores do poder punitivo do Estado, tais como intervenção mínima, subsidiariedade e ofensividade. A construção de normas penais não pode estar alicerçada em discursos falaciosos que busquem, tão somente, atender às expectativas da opinião pública.

Em segundo lugar, conclui-se que a Constituição Federal de 1988 determina a proteção penal do meio ambiente. Contudo, é necessário que o cumprimento da ordem constitucional seja feito à luz do direito penal como "ultima ratio", sob pena de violação a direitos e garantias fundamentais. Tal conclusão é possível, sobretudo, ao considerar que o direito penal é a única esfera capaz de exercer, coercitivamente, controle sobre o 
comportamento social e imiscuir-se nas liberdades individuais, evidenciando a necessidade de maior racionalidade da produção legislativa.

Ainda, é possível concluir que a proteção da fauna determinada na Constituição não faz distinção entre as espécies, em razão do reconhecimento do meio ambiente ecologicamente equilibrado como direito fundamental. Apesar disso, o legislador optou por aumentar as penas de maus-tratos cometidos contra cães e gatos, sem justificativa, fazendo com a que a política criminal se molde conforme às exigências de seu público.

Conclui-se, também, que a Lei 14.064/20 é dotada de alto grau de simbolismo em sua criação. A um porque restringiu a qualificadora aos crimes praticados aos cães e gatos, o que vai de encontro à Constituição Federal que determina a proteção da fauna. A dois porque, ao longo de todo o processo de tramitação da proposta legislativa, diversos casos de repercussão midiática nacional, mobilizando a sociedade à demandar por maior recrudescimento de pena, foram utilizados para justificar a aprovação da lei. A três porque, dois dias após publicação da lei, os meios de comunicação noticiaram a primeira prisão decorrente da Lei 14.064/20, indicando tentativa de prestar satisfação à sociedade sobre a eficácia do recrudescimento da pena.

Sem pretensão de relativizar a importância do meio ambiente e da proteção da fauna, conclui-se que a proposição legislativa para criminalização de condutas ou recrudescimento de penas deve ser acompanhada de dados concretos que a justifiquem, distanciando-se do discurso simbólico e aproximando-se da utilidade prática da norma penal, evitando-se crise de legitimação do Direito Penal e, por consequência, do Estado Democrático de Direito.

Como conclusão derradeira, tem-se que o grau de simbolismo empregado na aplicação da lei demanda por estudo quantitativo, capaz de avaliar os impactos da lei penal nas taxas de crimes contra os animais, não sendo possível avaliar a eficácia da legislação com base em notícias veiculadas nos meios de comunicação.

\section{REFERÊNCIAS}

AGUIAR, Lúcia Frota Pestana de. Avanço, com especismo seletivo na "Lei Sansão" (Lei 14.064/20). Direito em Movimento, Rio de Janeiro, v. 18 - n. 2, p. 215-222, 2º sem. 2020. Disponível em: http://emerj.com.br/ojs/seer/index.php/direitoemmovimento/article/view/313/84. Acesso em: 31 mar. 2021. 
ALVES, Amanda Bastos. Dos crimes contra o sistema financeiro nacional como expressão do direito penal simbólico no Brasil. 2016. 235f. Dissertação (Mestrado) Universidade Federal de Minas Gerais, Belo Horizonte, 2016. Disponível em: https://repositorio.ufmg.br/handle/1843/BUOS-ASJEFA. Acesso em: 31 mar. 2021.

BITENCOURT, Cezar Roberto. Tratado de Direito Penal: parte geral. Vol. 2. 12ed. São Paulo: Saraiva. 2012.

BRASIL. Câmara dos Deputados. Diário oficial da Câmara dos Deputados de 18 de dezembro de 2019 - p. 930-938. Disponível em: http://imagem.camara.gov.br/Imagem/d/pdf/DCD0020191218002280000.PDF\#page=930. Acesso em: 01 abr. 2021.

BRASIL. Câmara dos Deputados. Projeto de lei no 1.095 de dezembro de 2019. Altera a Lei $\mathrm{n}^{\circ}$ 9.605, de 12 de fevereiro de 1998 para estabelecer pena de reclusão a quem praticar ato de abuso, maus-tratos, ferir ou mutilar animais silvestres, domésticos ou domesticados, nativos ou exóticos; e instituir penas para estabelecimentos comerciais ou rurais que concorrerem para a prática do crime. Disponível em:

https://www.camara.leg.br/proposicoesWeb/prop_mostrarintegra;jsessionid=node017olnxh19 mtws11bgtda2hvb012123950.node0?codteor $=1714454 \&$ filename=TramitacaoPL+1095/2019. Acesso em: 25 mar. 2021.

BRASIL. Câmara dos Deputados. Regimento Interno da Câmara dos Deputados. Disponível: https://www2.camara.leg.br/atividade-legislativa/legislacao/regimento-internoda-camara-dos-deputados. Acesso em: 01 abr. 2021.

BRASIL. Constituição (1988). Constituição da República Federativa do Brasil. Brasília: Senado Federal, Centro Gráfico, 1988. 292p.

BRASIL. Código de Processo Penal (1941). Disponível em: Disponível em: http://www.planalto.gov.br/ccivil_03/decreto-lei/del3689compilado.htm. Acesso em: 26 mar. 2020.

BRASIL. Código Penal (1940). Disponível em: http://www.planalto.gov.br/ccivil_03/decreto-lei/del2848compilado.htm. Acesso em: 31 mar. 2020.

BRASIL. Lei 9.605, de 12 de fevereiro de 1998. Dispõe sobre as sanções penais e administrativas derivadas de condutas e atividades lesivas ao meio ambiente, e dá outras providências. Disponível em: http://www.planalto.gov.br/ccivil 03/leis/L9605.htm. Acesso em: 24 mar. 2021.

BRASIL. Lei 14.064, de 29 de setembro de 2020. Altera a Lei ${ }^{\circ} 9.605$, de 12 de fevereiro de 1998, para aumentar as penas cominadas ao crime de maus-tratos aos animais quando se tratar de cão ou gato. Disponível em: http://www.planalto.gov.br/ccivil_03/_ato20192022/2020/lei/L14064.htm. Acesso em: 25 mar. 2021. 
BRASIL. Lei n⿳ 9.099, de 26 de setembro de 1995. Dispõe sobre os Juizados Especiais Cíveis e Criminais e dá outras providências. Disponível em:

http://www.planalto.gov.br/ccivil_03/leis/19099.htm. Acesso em: 02 abr. 2021.

CACHORRO abandonado é envenenado e espancado por funcionário de Carrefour em Osasco, dizem ativistas. Portal G1, São Paulo, 04 dez. 2018. Disponível em:

https://g1.globo.com/sp/sao-paulo/noticia/2018/12/04/cachorro-abandonado-e-envenenado-eespancado-por-funcionario-de-hipermercado-em-osasco-dizem-ativistas.ghtml. Acesso em: 31 de mar. 2021.

CASO Manchinha: Carrefour terá de depositar R \$ 1 milhão em fundo para cuidados a animais. Portal G1, São Paulo, 15 mar. 2019. Disponível em: https://g1.globo.com/sp/saopaulo/noticia/2019/03/15/caso-manchinha-carrefour-tera-de-depositar-r-1-milhao-em-fundopara-cuidados-a-animais.ghtml. Acesso em: 31 de mar. 2021.

CACHORRO tem as patas decepadas a golpes de foice por vizinho em Confins. O Tempo, Belo Horizonte, 07 jul. 2020. Disponível em: https://www.otempo.com.br/cidades/cachorrotem-as-patas-decepadas-a-golpes-de-foice-por-vizinho-em-confins-1.2357345. Acesso em 02 de abril de 2021.

GALVÃO, Fernando. Direito penal: parte geral. 5ed. São Paulo: Saraiva. 2013.

MILARÉ, Edis. Direito do ambiente. 10. ed. rev. e atual. São Paulo: Revista dos Tribunais, 2014.

MORTE de cachorro em loja do Carrefour gera onda de protestos. Revista Exame, Osasco, 04 dez. 2018. Disponível em: https://exame.com/marketing/morte-de-cachorro-a-pauladasem-loja-do-carrefour-gera-onda-de-protestos/. Acesso em: 30 mar. 2021.

PRADO, Luiz Regis. Bem jurídico-penal e Constituição. 3ed. São Paulo: Revista dos Tribunais. 2003.

PRADO, Luiz Regis. Direito Penal do Ambiente. São Paulo: Revista dos Tribunais. 2005.

POLÍCIA Civil estoura 'rinha' de cães em Mairiporã e prende 41 pessoas. Portal G1, São Paulo, 15 dez. 2019. Disponível em: https://g1.globo.com/sp/sao-

paulo/noticia/2019/12/15/policia-civil-estoura-rinha-de-caes-em-mairipora-e-prende-40pessoas.ghtml. Acesso em 02 de abril de 2021.

SÁNCHEZ, Jesús-María Silva. A expansão do Direito Penal: aspectos da política criminal nas sociedades pós-industriais. $2^{\mathrm{a}}$ ed. rev. e amp. São Paulo: Revista dos Tribunais, 2011.

ZAFFARONI, Eugênio Raul et al. Direito Penal Brasileiro. Vol. 1. 4ed. São Paulo: Saraiva. 2011. 